\title{
Individual and Combined Effects of Alpha-amylase and Biocides on Biofilms Formed by Staphylococcus aureus Strains Isolated from Brazilian Dairy Farms
}

\section{Samuel Ferreira Gonçalves ${ }^{1}$, Sarah Hwa In Lee ${ }^{1}$, Lara Aguiar Borges ${ }^{2}$, Marta Liliane de Vasconcelos ${ }^{1}$, Carlos Humberto Corassin ${ }^{1}$ and Carlos Augusto Fernandes de Oliveira ${ }^{1 *}$}

${ }^{1}$ Departamento de Engenharia de Alimentos, Faculdade de Zootecnia e Engenharia de Alimentos, Universidade de São Paulo, Pirassununga, SP, Brazil

${ }^{2}$ Departamento de Tecnologia de Alimentos, Faculdade de Engenharia de Alimentos, Universidade Estadual de Campinas, Campinas, SP, Brazil

*Corresponding Author: Carlos Augusto Fernandes de Oliveira, 1Departamento de Engenharia de Alimentos, Faculdade de Zootecnia e Engenharia de Alimentos, Universidade de São Paulo, Pirassununga, SP, Brazil.
Received: September 14, 2021

Published: September 24, 2021

(C) All rights are reserved by Carlos Augusto

Fernandes de Oliveira., et al.

\begin{abstract}
This work aimed at evaluating the effect of alpha-amylase (AA, $100 \mathrm{mg} / \mathrm{mL}$ ), sodium hypochlorite (SH, 0.5\%), peracetic acid (PAA, 0.3\%), and enzyme-biocide combinations (SH or PAA and AA) on mono-species biofilms formed by four Staphylococcus aureus strains (P01F2T1, P01F5T2, P16 and P24) previously isolated from dairy farms in São Paulo state, Brazil. Biofilm formation index (BFI) and culturable cell counts were evaluated for biofilms formed on polystyrene microplates for $72 \mathrm{~h}$ at $25 \circ \mathrm{C}$. The BFI of isolates P16 and P24 significantly decreased (P < 0.05) after treatment with PAA or SH combined with AA, compared with the biocides alone. The biofilms formed by isolates P01F2T1 and P01F5T2 had lower BFI values $(\mathrm{P}<0.05)$ after treatment with combinations of PAA $+\mathrm{AA}$ and $\mathrm{SH}+\mathrm{AA}$, respectively. However, significant reductions in the biofilm culturable counts were observed only for isolates P01F2T1 treated with SH + AA and PAA + AA, P01F5T2 treated with SH + AA, and P24 treated with PAA + AA. Further studies are required to define the best combinations of AA and SH or PAA to completely remove $S$. aureus biofilms formed on plastic surfaces in processing dairy environments.
\end{abstract}

Keywords: S. aureus; Bacterial Adhesion; Peracetic Acid; Sodium Hypochlorite; Alpha-amylase

\section{Abbreviations}

AA: Alpha-amylase; BFI: Biofilm Formation Index; BHI: Brain Heart Infusion Broth; CFU: Colony-forming Unit; CIP: Cleaning in Place; EPS: Extracellular Polymeric Substances; L. monocytogenes: Listeria monocytogenes; nm: Nanometer; OD: Optical Density; PAA: Peracetic Acid; PBS: Phosphate Buffered Saline; P. aeruginosa: Pseudomonas aeruginosa; SH: Sodium Hypochlorite; S. aureus: Staphylococcus aureus; $\boldsymbol{\mu L}$ : Microliter.

\section{Introduction}

Staphylococcus aureus is a spherical-shaped, coagulase and catalase-positive bacterium with facultative anaerobic behavior [1].
S. aureus has been recognized as one of the main bacterial agents that cause foodborne diseases, due to the ingestion of its enterotoxins produced during growth on foods [2]. The disease caused by $S$. aureus enterotoxins are characterized by unpleasant symptoms such as nausea, vomiting, colic and diarrhea [3]. In dairy production systems, $S$. aureus is among the most important microrganims that require attention [4]. The contamination of milk may occur in dairy farms, from animals infected with clinical or subclinical mastitis [5], and at the industrial level during processing in dairy plants. In both dairy farms and dairy plants, the surfaces of equipment, utensils and other milk-contact surfaces such hands are considered the major sources of contamination of milk and dairy products [6]. 
Individual and Combined Effects of Alpha-amylase and Biocides on Biofilms Formed by Staphylococcus aureus Strains Isolated from Brazilian Dairy Farms

Several bacterial species including $S$. aureus are able to adhere to surfaces to guarantee the survival in an inhospitable environment, forming complex communities that are called biofilms [7]. Biofilms are defined as communities of sessile microbial life, which adhere to solid supports and produce extracellular polymeric substances (EPS) [8] that may contain polysaccharides, proteins, phospholipids and extracelular DNA (eDNA) [9]. After the initial adhesion on surfaces, the formation of mature biofilms occurs from three to six days, through an increase in the population density and the EPS content of biofilm [10]. This process increases the thickness of the adhered biofilm, thus providing a potential source of contamination by foodborne pathogens during food processing [11].

The control or eradication of biofilms in the food industry has been explored with the application of biocides such as sodium hypochlorite (SH) and peracetic acid (PAA) [12-14]. SH is a common biocide used in dairy farms, since it has a quick action, easy application and effective microbiological control [15]. In addition, SH also has an anti-microbial potential against $S$. aureus biofilms [16]. PAA is a broad-spectrum biocide that is widely used in dairy industries because it does not produce toxic waste and is considered environmentally friendly, when compared to other biocides [17]. However, microorganisms adhered to surfaces after biofilm formation are more resistant to biocides, such as SH and PAA, than non-adherent microorganisms $[17,18]$.

Enzymes are often used as complementary cleaning agents for biocides [19] being natural catalysts capable of accelerating chemical reactions [20]. Alpha-amylase (AA, $\alpha$-1,4-glucan-4glucan-hydrolase) is an enzyme found in humans, plants and microorganisms, being able to catalyze the hydrolysis reactions in the $\alpha$-1,4-glicosidic bonds in starch to the production of glucose and maltose [21], having action against $S$. aureus biofilms in inhibiting its formation [22]. Fleming., et al. [23] observed that the use of AA and cellulase solution against biofilms from $S$. aureus and $P$. aeruginosa significantly reduced the biomass of biofilms. In this context, it can be hypothesized that enzyme-biocide combinations may increase the effectiveness in removing the biofilms formed by pathogenic bacteria on surfaces. Thus, the present study aimed to evaluate the effect of SH, PAA, AA and enzyme-biocide combinations ( $\mathrm{SH}$ or PAA and $\mathrm{AA}$ ) on mono-species biofilms produced in polystyrene microplates by $S$. aureus strains previously isolated from dairy farms in São Paulo state, Brazil.

\section{Material and Methods}

\section{Staphylococcus aureus Isolates}

Four strains of S. aureus (P01F2T1, P01F5T2, P16 and P24) previously isolated and classified as strong biofilm producers by Lee., et al. [18] were used in this work. The isolates P01F2T1 and P01F5T2 were obtained from milk tanks of a dairy farm located in the area of Franca, state of São Paulo, while strains P16 and P24 were isolated from cow's milk and milking system respectively, both from farms located in Pirassununga, state of São Paulo, Brazil [18]. All strains were preserved in Trypticase Soy Broth (TSB, Oxoid) with $15 \%$ glycerol (v/v) and stored at $-80{ }^{\circ} \mathrm{C}$ until biofilm formation and subsequent treatments.

Effect of Biocides and Alpha-Amylase on Biofilms Formed on Polystyrene Microplates

Each strain of $S$. aureus was inoculated in $5 \mathrm{~mL}$ of Brain Heart Infusion broth (BHI, Oxoid) and incubated at $37^{\circ} \mathrm{C}$ for $24 \mathrm{~h}$. Subsequently, the culture was adjusted on a McFarland scale to $0.5\left(10^{8}\right.$ cells $/ \mathrm{mL}$ ) using uncultured BHI broth as blank. The production of biofilms followed the methodology described by Stepanovíc., et al. [24]. The bacterial isolates were transferred to 96-wells polystyrene microplates in triplicate volumes of $200 \mu \mathrm{L}$ for each well, and incubated at $25^{\circ} \mathrm{C}$ for $72 \mathrm{~h}$. After the incubation period, the optical density (OD) of the total bacteria in the microtiter plate was measured at $600 \mathrm{~nm}\left(\mathrm{OD}_{600 \mathrm{~nm}}\right)$ in an microplate reader (Labsystems, MultiSkan, USA). The broth and weakly adhered planktonic cells were removed, and each well was rinsed three times with 200 $\boldsymbol{\mu} \mathrm{L}$ of phosphate buffer saline (PBS) (pH 7.2). Next, $200 \mu \mathrm{L}$ of SH (Dinâmica, Diadema, Brazil) at $0.5 \%$ (v/v), or PAA (Dinâmica, Diadema, Brazil) at $0.3 \%(\mathrm{v} / \mathrm{v})$, or AA (Sigma-Aldrich, Saint Luis, MO) at $100 \mathrm{mg} / \mathrm{mL}$ were transferred to the wells and kept for $15 \mathrm{~min}$ for the removal of biofilms. The combined treatment of biocideenzyme ( $\mathrm{SH}$ and $\mathrm{AA}, \mathrm{PAA}$ and $\mathrm{AA}$ ) were carried out with the introduction of AA $(200 \mu \mathrm{L})$ in the wells for $5 \mathrm{~min}$, then discharging the enzyme and finally treating with $200 \mu \mathrm{L}$ of SH or PAA solution for $10 \mathrm{~min}$. After treatment, the wells were washed again with 200 $\mu \mathrm{L}$ of PBS to insert methanol (200 $\boldsymbol{\mu L}$ ) for $15 \mathrm{~min}$. The solvent was discharde and the wells were dried at room temperature. Twohundred $\mathrm{mL}$ of violet crystal solution $(0.1 \%, \mathrm{~m} / \mathrm{v})$ was inserted in each well for staining the adhered biofilms for $15 \mathrm{~min}$, followed by three subsequent washes with sterile distilled water. The microplates were dryed at room temperature for $15 \mathrm{~min}$, and the stained 
Individual and Combined Effects of Alpha-amylase and Biocides on Biofilms Formed by Staphylococcus aureus Strains Isolated from Brazilian Dairy Farms

biofilms adhered to the wells were re-solubilized by adding $200 \mu \mathrm{L}$ of glacial acetic acid. After $15 \mathrm{~min}$. incubation, the volumes were transferred to a new microplate and read in a microplate reader (Labsystems, MultiSkan, USA) at $570 \mathrm{~nm}\left(\mathrm{OD}_{570 \mathrm{~nm}}\right)$. The calculation of the biofilm formation index (BFI) was performed using the formula of Niu and Gilbert [25]:

Where $\mathrm{OD}_{570 \mathrm{~nm}}$ is obtained from disinfected (treated) or positive control wells (biofilm treated with PBS) after coloring; $\mathrm{OD}_{\mathrm{C570nm}}$ is obtained from negative control wells (treated with PBS) after coloring; $\mathrm{OD}_{600 \mathrm{~nm}}$ is obtained from the disinfected or positive control wells; and $\mathrm{OD}_{\mathrm{C} 600 \mathrm{~nm}}$ is obtained from negative control wells after 72 $\mathrm{h}$ of biofilm formation.

The efficiency of SH, PAA and AA and enzyme-biocide treatment was also evaluated by culturable cell counts in each well of the polystyrene microplates, following the methodology described by Srey., et al. [26]. Each S. aureus isolate in BHI broth was transferred in $200 \mu \mathrm{L}$ triplicates to 96-well polystyrene microplates and incubated for $72 \mathrm{~h}$. After this period, all planktonic cells and the broth were removed, and the wells were washed three times with 200 $\boldsymbol{\mu L}$ of PBS (pH 7.2). Each well was treated with the addition of 200 $\mu \mathrm{L}$ of SH $(0.5 \%, \mathrm{v} / \mathrm{v})$, PAA $(0.3 \%, \mathrm{v} / \mathrm{v})$ and AA $(100 \mathrm{mg} / \mathrm{mL})$ for 15 min, while the combined treatments $\mathrm{SH}$ and AA, PAA and AA were performed with the insertion of $\mathrm{AA}$ in the wells for $5 \mathrm{~min}$, followed by treatment with SH or PAA $(200 \mu \mathrm{L})$ for $10 \mathrm{~min}$. After the contact times with biocides, enzyme, or enzyme-biocide, the wells were emptied and soon thereafter, a sterile cotton swab was pressed at the bottom of the well and rotated 50 times clockwise and another 50 times counterclockwise. The swabs were placed in test tubes containing sterile PBS and left to rest for $5 \mathrm{~min}$, with each tube being shaken for $30 \mathrm{~s}$. Then, the contents of the tubes were subjected to serial dilutions to inoculate on Baird-Parker agar (Merck KGaA, Darmstadt, Germany) supplemented with egg yolk emulsion and tellurite (Oxid), about $0.1 \mathrm{~mL}$ of each dilution was incubated at 37 ${ }^{\circ} \mathrm{C}$ for $48 \mathrm{~h}$ before counting. The results were expressed as colony forming units per well (CFU/well).

\section{Statistical analysis}

The BFI values and colony counts obtained in the tests on polystyrene microplates with $\mathrm{SH}, \mathrm{PAA}, \mathrm{AA}, \mathrm{SH}+\mathrm{AA}$, and $\mathrm{PAA}+\mathrm{AA}$ were analyzed by unilateral analysis of variance [27]. The means of the treatments that showed significant differences were compared us- ing the Tukey test at $5 \%$ probability $(\mathrm{P}<0.05)$.

\section{Results and Discussion}

Table 1 presents the BFI values and their respective percentage reductions of biofilm-producing $S$. aureus isolates on polystyrene microplates after treatment with SH (0.5\%), PAA $(0.3 \%)$ and AA $(100 \mathrm{mg} / \mathrm{mL})$ and combinations of enzyme-biocides (SH + AA, PAA + AA). Compared with controls, biofilms formed by all $S$. aureus isolates had lower $(\mathrm{P}<0.05) \mathrm{BFI}$, with values of $0.33 \pm 0.05$ to $0.48 \pm$ 0.09 and percent reductions varying from $31.7 \pm 5.2$ to $52.9 \pm 3.4 \%$.

No differences $(\mathrm{P}>0.05$ ) were observed between the BFI values or percent reductions of biofilms produced by the four isolates of $S$. aureus treated with individual SH and PAA, except for isolate P24, which BFI for SH was higher than PAA. These results are consistent with those reported by Lee., et al. [18], who described that the use of PAA in the concentration of $0.5 \%$ efficiently removed the adhered cells of $S$. aureus from plastic materials. In another study, Chino., et al. [28] reported that PAA at $0.3 \%$ was efficient against $S$. aureus strains, although the authors observed that $S$. aureus biofilms were resistant to treatment with $\mathrm{SH}$ at a concentration of $0.1 \%$.

In our study, the treatment with AA only had BFI values similar to controls ( $\mathrm{P}>0.05)$ and mild reductions (up to $10.0 \pm 1.2 \%$ ) in biofilms, when compared to the other individual treatments $(\mathrm{SH}$ and PAA). However, the combination of AA with SH or PAA resulted in higher reductions $(\mathrm{P}<0.05)$ of $\mathrm{BFI}$ for biofilms formed by isolates P16 and P24, which values were $68.3 \pm 6.6$ and $66.3 \pm 9.0 \%$, respectively. The highest $(\mathrm{P}<0.05)$ BFI reduction $(79.8 \pm 8.4 \%)$ was achieved with the combination of PAA and AA on biofilms formed by the isolate P01F2T1, while isolate P01F5T2 had greater BFI reduction $(\mathrm{P}<0.05)$ after treatment with $\mathrm{SH}$ and $\mathrm{AA}(70.7 \pm$ 9.1\%). Importantly, no treatment was able to completely reduce the BFI of biofilms formed by the $S$. aureus isolates evaluated in this work.

S. aureus biofilms have greater resistance to the sanitization process, resulting in less inhibition and removal on surfaces such as stainless steel and glass [29], but especially in polystyrene and polypropylene [30]. Souza., et al. [31] observed that PAA (30 mg/L) and SH $(250 \mathrm{mg} / \mathrm{L})$ were not efficient in removing adhered $S$. aureus cells on polypropylene and stainless steel surfaces incubated 
Individual and Combined Effects of Alpha-amylase and Biocides on Biofilms Formed by Staphylococcus aureus Strains Isolated from Brazilian Dairy Farms

91

\begin{tabular}{|c|c|c|c|c|c|c|c|c|}
\hline \multirow[b]{2}{*}{ Treatment } & \multicolumn{2}{|c|}{ Isolate P01F2T1 } & \multicolumn{2}{|c|}{ Isolate P01F5T2 } & \multicolumn{2}{|c|}{ Isolate P16 } & \multicolumn{2}{|c|}{ Isolate P24 } \\
\hline & BFI $^{1}$ & $\begin{array}{c}\text { Reduction }^{2} \\
(\%)\end{array}$ & $\mathbf{B F I}^{1}$ & $\begin{array}{c}\text { Reduction }^{2} \\
(\%)\end{array}$ & BFI $^{1}$ & Red & BFI $^{1}$ & $\begin{array}{c}\text { Reduction }^{2} \\
(\%)\end{array}$ \\
\hline Control & $0.70 \pm 0.09^{a}$ & - & $0.65 \pm 0.02^{\mathrm{a}}$ & - & $0.63 \pm 0.04^{a}$ & - & $0.70 \pm 0.01^{\mathrm{a}}$ & - \\
\hline $\mathrm{SH}$ & $0.35 \pm 0.06^{b}$ & $50.4 \pm 5.5^{b}$ & $0.39 \pm 0.12^{b}$ & $44.8 \pm 6.1^{c}$ & $0.33 \pm 0.17^{b}$ & $52.4 \pm 9.6^{b}$ & $0.48 \pm 0.09^{b}$ & $31.7 \pm 5.2^{b}$ \\
\hline PAA & $0.37 \pm 0.06^{b}$ & $46.7 \pm 4.7^{b}$ & $0.37 \pm 0.16^{b}$ & $46.5 \pm 7.3^{c}$ & $0.33 \pm 0.05^{b}$ & $52.9 \pm 3.4^{b}$ & $0.39 \pm 0.05^{c}$ & $44.4 \pm 5.4^{b}$ \\
\hline $\mathrm{AA}$ & $0.70 \pm 0.09^{a}$ & 0 & $0.63 \pm 0.03^{a}$ & $10.0 \pm 1.2^{\mathrm{d}}$ & $0.73 \pm 0.14^{\mathrm{a}}$ & 0 & $0.68 \pm 0.02^{a}$ & $3.1 \pm 0.1^{c}$ \\
\hline $\mathrm{PAA}+\mathrm{AA}$ & $0.14 \pm 0.08^{\mathrm{c}}$ & $79.8 \pm 8.4^{a}$ & $0.31 \pm 0.08^{b c}$ & $55.9 \pm 3.4^{b}$ & $0.22 \pm 0.05^{c}$ & $68.3 \pm 6.6^{\mathrm{a}}$ & $0.24 \pm 0.11^{\mathrm{c}}$ & $66.3 \pm 9.0^{a}$ \\
\hline
\end{tabular}

Table 1: Biofilm formation index (BFI) and percentage reduction of monospecies biofilms formed by Staphylococcus aureus isolates on polystyrene microplates, after treatment with sodium hypochlorite ( $\mathrm{SH}, 0.5 \%$, v/v), peracetic acid (PAA, 0.3\%, v/v) and alpha-amylase

$(\mathrm{AA}, 100 \mathrm{mg} / \mathrm{mL})$, alone or in combination.

${ }^{1}$ Results are reported as mean \pm standard deviation of triplicate assays.

${ }^{2}$ Percentage calculated in relation to the control (biofilm treated with phosphate buffer solution).

${ }^{\mathrm{a}-\mathrm{d}}$ In the same column, means followed by different letters differ significantly $(\mathrm{P}<0.05)$.

for $72 \mathrm{~h}$, conditions similar to the present study in the production of mature biofilms, where the biocides were not able to completely remove the adhered biofilms. In this context, the insertion of enzymes in combination with biocides offers an alternative for the removal of biofilms on surfaces, through mechanisms such as the degradation of the biofilm matrix components, which facilitates the inactivation and removal of cells during cleaning procedures [22,32].

The greater effect of combined treatments with enzyme and biocide compared with individual treatments on biofilms of $S$. $a u$ reus on polystyrene microplates cultivated for $72 \mathrm{~h}$ was confirmed by culturable cell count, as illustrated in table 2 .

Individual SH or PAA treatments of all $S$. aureus isolates tested resulted in lower counts $(P<0.05)$ of their respective planktonic cells (range: $2.00 \pm 0.4$ to $3.60 \pm 0.4 \mathrm{CFU} /$ well), when compared with the controls (range: $4.37 \pm 0.6$ to $5.74 \pm 0.7 \mathrm{CFU} /$ well). However, lower counts $(P<0.05)$ were observed for the combined treatments $(\mathrm{SH}+\mathrm{AA}, \mathrm{PAA}+\mathrm{AA})$. The counts for the treatment of combined SH and AA ranged from $1.95 \pm 0.2$ to $2.51 \pm 0.7 \log \mathrm{CFU} /$ well, while the values for biofilms treated with PAA and AA varied from $1.30 \pm 0.4$ to $2.41 \pm 0.4 \log \mathrm{CFU} /$ well. These results are coherent with the BFI obtained for the treated biofilms (Table 1), in which the PAA and AA treatment demonstrated higher reductions in biofilms. Araújo., et al. [33] also observed that the associated use of protease and cetyl trimethyl ammonium bromide (CTAB) against biofilms of Pseudomonas fluorescens increased the reduction in about $1.93 \log \mathrm{CFU} / \mathrm{cm}^{2}$, thus corroborating our findings on the use of enzymes as potential complementing agents to commercial biocides for reducing biofilms on surfaces.

Compared with controls, AA (100 mg/mL) alone had non-significant effects on the culturable cell counts of $S$. aureus, resulting in smaller reductions of biofilms varying from $2.41 \pm 0.4$ to $12.4 \pm$ $2.0 \%$. Accordingly, Mnif., et al. [34] found that in high concentrations (500 mg/mL) of amylases were not effective against Macrococcus caseolyticus biofilms. In contrast, Craigen., et al. [35] observed that the use of AA on biofilms of $S$. aureus formed during 18 $\mathrm{h}$ led to a reduction of $79 \%$. In the present study, the mild effect of AA on mature biofilms after $72 \mathrm{~h}$ may be explained by the higher degree of biofilm formation, which provides greater protection for the biofilm and hamper its removal from surfaces due to the polymeric matrix composed by polysaccharides, eDNA and proteins [10,36]. Oliveira., et al. [37] observed that maturation of L. monocytogenes ATCC 19111 biofilms was completed 72 to 144 hours after the initial adhesion to surfaces, during which the growth of the cell population density resulted in and increased thickness of the biofilm. Consequently, mature biofilms are more resistant to individual SH or PAA treatments, when compared with planktonic microbial cells $[17,18]$. 
Individual and Combined Effects of Alpha-amylase and Biocides on Biofilms Formed by Staphylococcus aureus Strains Isolated from Brazilian Dairy Farms

\begin{tabular}{|c|c|c|c|c|c|c|c|c|}
\hline \multirow[b]{2}{*}{ Treatment } & \multicolumn{2}{|c|}{ Isolate P01F2T1 } & \multicolumn{2}{|c|}{ Isolate P01F5T2 } & \multicolumn{2}{|c|}{ Isolate P16 } & \multicolumn{2}{|c|}{ Isolate P24 } \\
\hline & $\begin{array}{l}\text { Count (Log } \\
\text { CFU/well) }{ }^{1}\end{array}$ & $\begin{array}{c}\text { Reduction }^{2} \\
(\%)\end{array}$ & $\begin{array}{l}\text { Count (Log } \\
\text { CFU/well) }{ }^{1}\end{array}$ & $\begin{array}{c}\text { Reduction }^{2} \\
(\%)\end{array}$ & $\begin{array}{l}\text { Count (Log } \\
\text { CFU/well) }^{1}\end{array}$ & $\begin{array}{c}\text { Reduction }^{2} \\
(\%)\end{array}$ & $\begin{array}{l}\text { Count (Log } \\
\text { CFU/well) }^{1}\end{array}$ & $\begin{array}{c}\text { Reduction }^{2} \\
(\%)\end{array}$ \\
\hline Control & $4.46 \pm 0.3^{a}$ & - & $4.37 \pm 0.6^{a}$ & - & $5.74 \pm 0.7^{a}$ & - & $4.99 \pm 0.8^{a}$ & - \\
\hline $\mathrm{SH}$ & $2.70 \pm 0.1^{b}$ & $39.5 \pm 2.0^{b}$ & $3.60 \pm 0.4^{b}$ & $19.2 \pm 1.8^{\mathrm{d}}$ & $2.00 \pm 0.4^{b}$ & $65.2 \pm 1.3^{\mathrm{a}}$ & $2.32 \pm 0.2^{c}$ & $53.5 \pm 4.8^{b}$ \\
\hline PAA & $2.45 \pm 0.2^{b}$ & $45.2 \pm 2.4^{c}$ & $2.65 \pm 0.5^{b c}$ & $40.6 \pm 1.6^{c}$ & $2.95 \pm 0.6^{b}$ & $48.6 \pm 1.6^{c}$ & $2.97 \pm 0.1^{b}$ & $40.45 \pm 2.5^{c}$ \\
\hline AA & $4.00 \pm 0.5^{\mathrm{a}}$ & $10.3 \pm 0.7^{d}$ & $4.36 \pm 0.7^{\mathrm{a}}$ & $2.1 \pm 0.2^{\mathrm{e}}$ & $5.03 \pm 0.5^{\mathrm{a}}$ & $12.4 \pm 2.0^{\mathrm{d}}$ & $4.52 \pm 0.3^{\mathrm{a}}$ & $9.4 \pm 1.0^{d}$ \\
\hline $\mathrm{SH}+\mathrm{AA}$ & $2.00 \pm 0.8^{b c}$ & $55.2 \pm 1.7^{a}$ & $1.95 \pm 0.2^{\mathrm{d}}$ & $56.2 \pm 1.3^{a}$ & $2.51 \pm 0.7^{b}$ & $56.3 \pm 1.9^{b}$ & $2.00 \pm 0.6^{\mathrm{cd}}$ & $59.9 \pm 6.7^{b}$ \\
\hline $\mathrm{PAA}+\mathrm{AA}$ & $2.00 \pm 0.2^{c}$ & $55.2 \pm 1.3^{\mathrm{a}}$ & $2.41 \pm 0.3^{c}$ & $45.9 \pm 1.7^{b}$ & $2.41 \pm 0.4^{b}$ & $56.4 \pm 1.8^{b}$ & $1.30 \pm 0.4^{\mathrm{d}}$ & $73.9 \pm 4.1^{\mathrm{a}}$ \\
\hline
\end{tabular}

Table 2: Culturable cell counts and respective reductions of monospecies biofilms formed by Staphylococcus aureus isolates on polystyrene microplates, after treatment with sodium hypochlorite ( $\mathrm{SH}, 0.5 \%$, v/v), peracetic acid (PAA, 0.3\%, v/v) and alpha-amylase (AA, $100 \mathrm{mg} / \mathrm{mL}$ ), alone or in combination.

${ }^{1}$ Results are reported as mean \pm standard deviation of triplicate assays.

${ }^{2}$ Percentage calculated in relation to the control (biofilm treated with phosphate buffer solution).

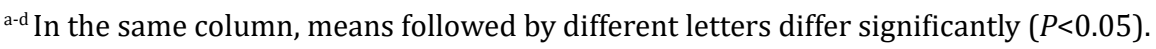

The formation and survival of $S$. aureus biofilms in dairy environments are directly related to the physical-chemical characteristics of milk, since compounds such as vitamins, minerals and calcium participate directly in the formation of residues on surfaces and pipes, contributing to microbial growth on the spot [38]. In this context, in order to prevent biofilms from reaching the mature stage, unit operations such as cleaning in place (CIP) are considered as the best control strategy in the food industry [16]. S. aureus cells have great capacity to form biofilms on polystyrene and stainless steel surfaces, due to crucial factors in microbial adhesion such as hydrophobicity on the surface [18]. This adhesion and subsequent biofilm formation provide the conditions for survival of the bacterial cells in the environment, also decreasing the efficacy of CIP procedures in the food processing environment [39]. In the present study, a partial reduction of mature biofilms of $S$. aureus isolates was observed after treatments with SH $(0.5 \%)$ or PAA $(0.3 \%)$. The fact that these commercial biocides widely used in food industries were not effective against $S$. aureus strains isolated from dairy farms warrants concern on their persistance in dairy industries. Although the combined enzyme-biocide treatments did not achieve complete reduction of $S$. aureus mature biofilms, the increased reduction provided by $\mathrm{SH}+\mathrm{AA}$ or PAA $+\mathrm{AA}$ indicated a promising strategy that could be useful for cleaning equipment, utensils and other surfaces in dairy processing environments.

\section{Conclusion}

Mature biofilms formed on polystyrene plates by four S. aureus isolated from dairy farms were partially reduced after treatments with SH $(0.5 \%, v / v)$ or PAA $(0.3 \%, v / v)$, while AA $(100 \mathrm{mg} / \mathrm{mL})$ was not effective for biofilm reduction. However, higher reductions in the BFI and in biofilm culturable counts were observed in biofilms treated with $\mathrm{SH}+\mathrm{AA}$ or $\mathrm{PAA}+\mathrm{AA}$. Although any treatment studied was able to completely remove $S$. aureus biofilms on polystyrene, the biocide-enzyme combinations evaluated in this study offer a promising strategy to increase the efficiency of CIP procedures, especially when applied on surfaces that come into direct contact with food. Further studies on the enzyme-biocide combination on mature biofilms are required to define efficient treatments for the complete removal of pathogens such as S. aureus.

\section{Acknowledgements}

The authors thank the Conselho Nacional de Desenvolvimento Científico e Tecnológico (CNPq, Grant 306304/2017-1), for financial support. This study was financed in part by the Coordenação de Aperfeiçoamento de Pessoal de Nível Superior-Brasil (CAPES), finance code 001.

\section{Competing Interests}

The authors declare that there is no conflict of interest.

\section{Bibliography}

1. Gutiérrez D., et al. "Incidence of Staphylococcus aureus and analysis of associated bacterial communities on food industry surfaces". Applied and Environmental Microbiology 78.24 (2012): 8547-8554. 
2. Gonzalez AGM., et al. "Methicillin-resistant Staphylococcus aureus in Minas Frescal cheese: evaluation of classic enterotoxin genes, antimicrobial resistance and clonal diversity". FEMS Microbiology 364.23 (2017): fnx232.

3. Prezzi LE., et al. "Effect of Lactobacillus rhamnosus on growth of Listeria monocytogenes and Staphylococcus aureus in a probiotic Minas Frescal cheese". Food Microbiology 92 (2020): 103557.

4. Meesilp N and Mesil N. "Effect of microbial sanitizers for reducing biofilm formation of Staphylococcus aureus and Pseudomonas aeruginosa on stainless steel by cultivation with UHT milk". Food Science and Biotechnology 28 (2019): 289-296.

5. Melo PC., et al. "NaOCl effect on biofilm produced by Staphylococcus aureus isolated from the milking environment and mastitis infected cows". Pesquisa Veterinária Brasileira 34.2 (2014): 109-113.

6. Avila-Novoa MG., et al. "Biofilm formation by Staphylococcus aureus isolated from food contact surfaces in the dairy industry of Jalisco, Mexico". Journal of Food Quality (2018): 1746139.

7. Fleming HC., et al. "Biofilms: an emergent form of bacterial life”. Nature Reviews Microbiology 14.9 (2016): 563-575.

8. Yuan L., et al. "Mixed-species biofilms in the food industry: Current knowledge and novel control strategies". Critical Reviews in Food Science and Nutrition 60.13 (2020): 2277-2293.

9. Fulaz S., et al. "Nanoparticle-biofilm interactions: The role of the EPS matrix". Trends in Microbiology 27.11 (2019): 915926.

10. Weber M., et al. "Bacterial community composition of biofilms in milking machines of two dairy farms assessed by a combination of culture-dependent and independent methods". Plos One 14.9 (2019): e0222238.

11. Galié S., et al. "Biofilms in the food industry: Health aspects and control methods". Frontiers in Microbiology 9 (2018): 898.

12. Pagedar A and Singh J. "Evaluation of antibiofilm effect of benzalkonium chloride, iodophore and sodium hypochlorite against biofilm of Pseudomonas aeruginosa of dairy origin". Journal of Food Science and Technology 52.8 (2015): 53175322.
13. Poimenidou SV., et al. "Variability of Listeria monocytogenes strains in biofilm formation on stainless steel and polystyrene materials and resistance to peracetic acid and quaternary ammonium compounds". International Journal of Food Microbiology 237.21 (2016): 164-171.

14. Castro MR., et al. "Biofilm formation on stainless steel as a function of time and temperature and control through sanitizers". International Dairy Journal 68 (2017): 9-16.

15. Byun K-H., et al. "Efficacy of chlorine-based disinfectants (sodium hypochlorite and chlorine dioxide) on Salmonella enteritidis planktonic cells, biofilms on food contact surfaces and chicken skin". Food Control 123.2 (2021): 1-8.

16. Srey S., et al. "Biofilm formation in food industries: A food safety concern". Food Control 31.2 (2013): 572-585.

17. Lee SHI., et al. "Effect of peracetic acid on biofilms formed by Listeria monocytogenes strains isolated from a Brazilian cheese processing plant". Brazilian Journal of Pharmaceutical Sciences 53.3 (2017): e00071.

18. Lee SHI., et al. "Effect of peracetic acid on biofilms formed by Staphylococcus aureus and Listeria monocytogenes isolated from dairy plants". Journal of Dairy Science 99.3 (2016): 23842390.

19. Boels G. "Enzymatic removal of biofilms: a report". Virulence 2 (2011): 476-478.

20. Meireles A., et al. "The current knowledge on the application of anti-biofilm enzymes in the food industry". Food Research International 86 (2016): 140-146.

21. Sundarram A and Murthy TPK. " $\alpha$-Amylase Production and Applications: A Review". Journal of Applied and Environmental Microbiology 2.4 (2014): 166-175.

22. Thallinger B., et al. "Antimicrobial enzymes: An emerging strategy to fight microbes and microbial biofilms". Biotechnology Journal 8.1 (2013): 97-109.

23. Fleming D., et al. "Glycoside hydrolases degrade polymicrobial bacterial biofilms in wounds". Antimicrobial Agents and Chemotherapy 61.2 (2017): e01998.

24. Stepanović S., et al. "Biofilm formation by Salmonella spp. and Listeria monocytogenes on plastic surface". Letters in Applied Microbiology 38.5 (2004): 428-432. 
25. Niu C and Gilbert ES. "Colorimetric method for identifying plant essential oil components that affect biofilm formation and structure". Applied and Environmental Microbiology 70.12 (2004): 6951-6956.

26. Srey S., et al. "Evaluation of the removal and destruction effect of a chlorine and thiamine dilaurylsulfate combined treatment on L. monocytogenes biofilm". Foodborne Pathogens and Disease 11.8 (2014): 658-663.

27. Witte RS, Witte JS. Statistics. Wiley: Hoboken NJ (2017).

28. Chino T., et al. "Morphological bactericidal fast-acting effects of peracetic acid, a high-level disinfectant, against Staphylococcus aureus and Pseudomonas aeruginosa biofilms in tubing". Antimicrobial Resistance and Infection Control 6 (2017): 1-7.

29. Lee J-S., et al. "Biofilm formation of Staphylococcus aureus on various surfaces and their resistance to chlorine sanitizer". Journal of Food Science 80.10 (2015): 2279-2286.

30. Kim CY., et al. "Resistance of Staphylococcus aureus on food contact surfaces with different surface characteristics to chemical sanitizers". Journal of Food Safety 37.4 (2017): e12354.

31. Souza EL., et al. "Biofilm formation by Staphylococcus aureus from food contact surfaces in a meat-based broth and sensitivity to sanitizers". Brazilian Journal of Microbiology 45.1 (2014): 67-75.

32. Gonçalves SF, et al. "Enzyme-based approaches to control microbial biofilms in dairy processing environments: A review". Quality Assurance and Safety of Crops and Foods 12 (2020): 5058.

33. Araújo PA., et al. "Combination of selected enzymes with cetyltrimethylammonium bromide in biofilm inactivation, removal and regrowth". Food Research International 95 (2017): 101107.

34. Mnif S., et al. "Enzyme-based strategy to eradicate monospecies Macrococcus caseolyticus biofilm contamination in dairy industries". International Dairy Journal 100 (2020): 104560.

35. Craigen B., et al. "The use of commercially available alpha-amylase compounds to inhibit and remove Staphylococcus aureus biofilms". The Open Microbiology Journal 5 (2011): 21-31.

36. Combrouse T., et al. "Quantification of the extracellular matrix of the Listeria monocytogenes biofilms of different phylogenic lineages with optimization of culture conditions". Journal of Applied Microbiology 114.4 (2013): 1120-1131.
37. Oliveira MMM., et al. "Biofilm formation by Listeria monocytogenes on stainless steel surface and biotransfer potential". Brazilian Journal of Microbiology 41 (2010): 97-106.

38. Miguel EM., et al. "Formação de biofilmes em trocadores de calor e seus efeitos em leite e derivados". Revista do Instituto de Laticínios Cândido Tostes 69.1 (2014): 53-63.

39. Liu J., et al. "Surfactin effectively inhibits Staphylococcus aureus adhesion and biofilm formation on surfaces". Applied Microbiology and Biotechnology 103.11 (2019): 4565-4574.

\section{Volume 4 Issue 10 October 2021 (C) All rights are reserved by Carlos Augusto Fernandes de Oliveira., et al.}

